\title{
Pain and disease according to integral anthroposophical dentistry*
}

\section{Célia Regina Lulo Galitesi(a) Flaviana Bombarda de Andrade(b) Ana Flávia Sanches Borges ${ }^{(b)}$}

(a) Brazilian Association of Anthroposophical Dentistry - IDEIA, São Paulo, SP, Brazil.

(b) Department of Operative Dentistry, Endodontics and Dental Materials, Bauru School of Dentistry, Univ de São Paulo USP, Bauru, SP, Brazil.

\footnotetext{
* Paper presented at the "Oral Health Under an Integrality Perspective" International Symposium, held at the $17^{\text {th }}$ Congress of the Brazilian Association for Oral Health Promotion (ABOPREV), May 31 to June 2, 2012, Salvador, BA, Brazil.
}

Declaration of Interests: The authors certify that they have no commercial or associative interest that represents a conflict of interest in connection with the manuscript.

Corresponding author:

Célia Regina Lulo Galitesi

E-mail: lulogalitesi@uol.com.br

Submitted: Sep 28, 2012

Accepted for publication: Oct 08,2012

Last revision: Nov 08, 2012
Abstract: From an academic standpoint, the university format, in general, has been nurturing a "paradigm of expertise" and, consequently, the relationship between specialties has declined. The upshot is that recent college dental graduates have adopted a clinical performance focusing on system parts and their specificities, in detriment to a more comprehensive view of the mouth and of the patient as a whole, with his/her vital, emotional and individual attributes. An interaction between the several different areas of human knowledge is needed imminently to decrease the dichotomy in professional behavior, because the demand for professionals and dental patients interested in a more comprehensive approach are increasing day by day. Patients want to know: "What, in fact, is behind the etiological extrinsic and intrinsic factors that maintain neuropathic pain, recurrent thrush, or persistent halitosis," among other questions, "even under the care of a dentist?" or "Why is this disease affecting me?"

There are several issues composing the paradigm of salutogenesis: What are the essential aspects that constitute a healthy individual, overlapping the usual investigation: How to destroy, avoid and quell the pathological agents?

A proposed approach is based on salutogenesis, which examines such issues. According to this approach, anthroposophical dentistry includes determinant factors, determinants of health, basic research and the development of oral health promotion, thus connecting dental academia with integrative thinking, while also complementing and gathering information that subsidizes basic research with the primordial concepts on laws governing the parameters involved in the vital processes of nature.

Descriptors: Dentistry; Health Promotion; Comprehensive Dental Care; Anthroposophy.

\section{Introduction}

Brazilian dentistry is considered one of the world's best ${ }^{1}$ however, conventional dental work tends to emphasize external procedures, and underscores how the body processes the assimilation of individual substances, and also how the world views the manner in which the patient conceives and organizes his/her internal universe.

Holistic thinking (holo: Greek term meaning "whole" or "integer") is deeply ecological. The individual and nature are not separate forms. A whole cannot be dissociated. Quantum physics also shares the same bases in regard to the process of man's conscience. 
Not only are the parts of each system completebecause we all have the same origin in nature-but the laws governing the archetypal principles of the whole exist in each of its parts, and all phenomena interpenetrate the organic whole, and are alive and closely connected with the spiritual world. Thinking holistically requires the discovery of unifying principles that weave parts into a whole. ${ }^{2}$ The human being is a microcosm that has all of the macrocosmic processes within it. Accordingly, the teeth represent a microcosm relating to the macrocosm of the human body.

This alludes to the contexts and complexities that relate to each other in a process of dynamic action and reaction that connects what is internal and external. This is the basis of immunity and physical-spiritual-soul integrity, where the state of illness or pain is understood as a rupture of one of these levels. Healing is reconciliation, so as to overcome duality and separation. This study is a starting point to understand pain and disease, as we see it.

A single oral disease may manifest itself in different people for several reasons. The primary source reflects the changes in other organs or at other levels. For example, gum disease may occur in a person as a result of simply neglecting oral hygiene, whereas in other people it may be related to systemic disorders, such as diabetes, ${ }^{3}$ which requires systemic care. Similarly, a sum of factors may indicate emotional problems, or physical, psychological and social disorders.

Traditional dentistry constructs its procedures through agreements for pipelines and prescription drugs that are usually standardized. These agreements are entered into by a staff of people, according to a pathogenic model. This is partly due to the general difficulties inherent in the prevailing scientific paradigm, when function fulfills the agenda of economic and political interests, which call for practical and immediate results.

Currently, qualitative ${ }^{4}$ variables and quantitative research are starting to be employed, but are not achieving the breadth and depth required to contextualize the human being to his/her fullest. Simultaneously, the investigation of sociocultural factors influencing behavior brings us closer to understand- ing the etiology of pain and suffering related to oral diseases. With this in mind, a comprehensive line of integrative healthcare and therapy research ${ }^{5}$ must be followed and must include different educational strategies, ${ }^{6}$ as has been done in anthroposophical medicine.

Based on the proposed salutogenesis, ${ }^{7}$ anthroposophical dentistry ${ }^{8}$ should include determinants of health, primary research and development of oral health promotion among its fundaments.

\section{Integrative complementary approach}

Anthroposophical dentistry, ${ }^{9}$ named for official purposes, Integral Anthroposophical Dentistry (Odontologia Integral Antroposófica - OIA), uses an interdisciplinary approach, analytical interpretation, a salutogenic focus, and systemic and anthroposophical philosophy; it is based on the Goethean phenomenological method. ${ }^{10}$ It discusses the development of dentition to understand the tooth as part of a whole body, related to a larger system. In forming this system, organs and human beings partake in archetypal forces from the mineral, vegetable and animal kingdoms. ${ }^{8}$

Anamnesis is conducted by anthroposophical dentistry in the conventional academic sense, which includes investigating clinical signs and taking the patient's history. Laboratory tests, specific diagnoses, and treatment planning are conducted according to nutritional-hygienic and prophylactic guidelines. ${ }^{8}$ Disease is not something that affects someone exclusively on the outside, as though it were an outsider to the physiological process latent state. Treatment thus depends on simultaneous investigation of the specific occurrences of the diseases and the biological, emotional, intellectual, social and biographical profile of the patient, including his world of beliefs and perceptions, his sense of coherence and his/her resilience capabilities.

Information on nutrition, medications, habits, environment, education (pedagogy), stress and rhythm are collected in order to check the vital, emotional and conscious status regarding the physical body, because the oral environment and dietary conditions exert a powerful influence, and the ulti- 
mate fate of the tooth is determined by both intrinsic and extrinsic factors.

This thorough, integral contextualization is justified by the fact that illness and pain are directly related to the dissociation between the different degrees of intensity and subtle organizations manifested by the physical body.

Anthroposophical fundamentals aimed at health and education emerged in Europe in the early twentieth century, based on works by philosopher $\mathrm{Ru}$ dolf Steiner, ${ }^{11}$ who, in turn, was influenced by the research of Johann Wolfgang Goethe.

\section{Faces of pain}

Pain may manifest itself as an ally, as a warning, sometimes as an educator in life, pointing to the factor(s), correction(s) and need(s) for development, sometimes as a devitalizing process for chronic ailments, and, sometimes, even as a driver of psychological motivation to solve somatic conditions.

Pain and illness are primarily opportunities for behavioral changes; consequently, interdisciplinary work is of great relevance. As we strive to overcome them, we are strengthened.

\section{Pain-illness interface: suppression versus supply}

The form and the path chosen to resolve pain or disease, as proposed in this study, are as important as its actual resolution. The therapy used to suppress the symptoms only masks them. Postponing the future manifestation of these symptoms may cause their recurrence in the same manner and place, or transform them in such a way that they will affect other systems. This highlights the need for including a larger context of health determinants in the analysis.

In some patients, determining the nature of the pain under study is a difficult task, since pain may be central, neuropathically peripheral, nociceptive, or psychogenic. The coexistence of more than one type of pain may be a challenge in performing differential diagnosis, as in ataxic and paretic patients, and may require the understanding of a great number of accessory muscle and nociceptive pain triggers. ${ }^{11}$

Differential diagnosis is conducted to deter- mine the nature of the nociceptive, neuropathic or psychogenic pain, in order to delineate the prognosis, define the therapy, and extend the anamnesis through anthroposophical dentistry. In so doing, the phenomena that are not highly valued in conventional academic research are now observed. Examples include:

- the mood prevailing in the individual's behavior,

- the connection with the oral part of his temperament, and

- the relationship of the teeth ${ }^{12}$ to the constitutional type prevailing over a period of seven years, among others.

These factors allow us to detect the patient's pathological tendencies.

The oral conditions and their resulting pain are expressed in the cephalic pole as opposed to the motor-metabolic pole. Understanding the dynamics and characteristics of this duality according to the Goethean approach is the first step.

\section{The cephalic pole versus motor- metabolic duality: characteristics, dynamics, definitions and pathological tendencies}

We noted that the formation of the head is highly complex, because it contains bodies of greater longevity but lower regenerative potential, particularly teeth. $^{2}$

The head has a concentrated movement at its core, as well as mineralization, hardness and low repair; it is characterized by internalization, immobility and cooling, related to the scope of thought, cognition and consciousness, through system loss.

Conversely, there is the so-called metabolic pole, represented by the locomotor-metabolic system that embraces the sexual organs and most vital organs in general. The predominant structure of this system is one of radial action and expansion, trending toward mobility, high repair and anabolism, growth, reproduction, exteriorization of life, heat, dissolution and chaos, as compared to the scope of volition and action.

The anthroposophical approach considers the archetype processes of salt and sulfur-mediated 
mercury. The salt concentration leads to the mineral state (earth). Sulfur leads to dispersion and heat (fire). However, it is important to consider mercurysulfur salt-like processes. The mercurial process is a mediator between the correlatives of acid-base, hot-cold, nerve-blood, anabolism-catabolism and inflammation-sclerosis. As in the human soul, the mercurial process is related to the feeling, mediating the thinking process (salt), and wanting (sulfur), whereas the physical body has the rhythmic system mediator between the sensory neural pole and the metabolic motor pole, redeeming the human condition from a polar to ternary organization.

This source promotes therapy, ranging from the understanding of the constitutional type, to the nature of the pain (chronic/acute), and to the detection of pathological tendencies between the salt and the sulfurous archetypes, such as fluorosis, neuralgia, gingivitis, caries, pulpitis and sclerosis, among others.

Hippocratic medicine classified diseases into two basic groups: plethora and emptiness, i.e., intensification and weakening of the physiological processes before the diseases occurs. Alchemy, as well as several peoples, such as Native Americans, Indians, Chinese, African people, etc., embraces the notion that disease and ethnomedicine are based on a neutralization process, e.g., "cold" through "hot" and vice versa.

Integral human beings, according to the concepts of anthroposophy, consist of four organizations linked to the realms of nature, i.e., the four natural elements, which display the principle of metamorphosis. According to this principle, earth, water, air and fire are different manifestations of a common phenomenon related to the melancholic (earth), phlegmmatic (water), sanguine (air), and choleric (fire) temperaments, ${ }^{8}$ respectively, and, to the pulmonary, hepatobiliary, genitourinary, and circulatory systems, respectively, corresponding to the physical-mineral, vital (etheric), astral (psychic, emotional) and "I" (warm human individuality) bodies.

According to Goethean methodology, we will note that the etheric, astral and individual bodies are not mere abstractions related to the physi- cal body, they are well-structured organizations or bodies that appear respectively in the physical body, through bodies of water, air and diet.

For example, the typical picture of an observable phenomena-such as inflammatory redness (hyperemia, flow of substances), tumor (edema, fluid leakage, cell proliferation, granulation tissue [leukocytes, histiocytes]), pain (oxidation, feeling, acidity, phagocytosis, protein catabolism [histamine, serotonin]), heat (local hyperthermia, fever)—is related to physical, etheric, astral, and individual (I) organizations, respectively. Although the phenomena interpenetrate and manifest themselves simultaneously, we can point out links, such as that of flushing with the accumulation of substances in the body, a process more directly linked to the mineral world. Tumor and edema-the etheric body-are linked to the mechanism of organic liquids (water body) and therefore to vitality. Pain and tenderness-the astral body-are linked to air and gas, which in turn guide our inspirational and emotional life. Heat is linked to the capability of organization, which sets us apart as warm-blooded animals. The evolutionary scale gives us freedom, conscience and autonomy.

We believe that a "closed treatment" to combat, prevent or suppress a disease or pain is an incomplete and increasingly more restricted rationality. We can assay the concept of illness or pain as a resulting state of the constant struggle between the impact of the external action of the external world, and how it is being processed and organized in the internal world.

\footnotetext{
"Understanding a person only through the mouth is fragmenting science; understanding a human being without the mouth is reducing science; and understanding the individual without nature is distorting science." 8
}

The interdiciplinary non-medicinal therapy used in anthroposophical dentistry addresses the oral cavity, makes ternary and quaternary systemic associations with the teeth, and includes the study of human development, based on the concept of comparative anatomy within the species. This concept advocates caring reciprocally for the three different levels of the human being: 
- Individual level: treated conventionally with cognitive therapy; it can be treated with anthroposophical therapy, using biographical questions to support the scope of consciousness and selfconsciousness.

- Psychic level: as per the view of psychologists, art therapists, and others.

- Somatic level: including speech therapy, nutrition, medicine, physiotherapy, pharmacy and nursing, among others.

Completing the diagnosis of an oral disease by way of clinical history is a full and extensive anthroposophical dental analysis. ${ }^{8}$ This implies that the dentist has detected and classified the etiological factors of the physical and other levels. The therapy planning for this analysis calls for the treatment of strictly oral issues (treated by a dentist) simultaneously with the treatment of the related issues identified. This analysis should be forwarded to another healthcare professional (e.g., physician), so that he may adopt an interdisciplinary therapy together with the dentist, and thus interact in proposing a cure or remission of the pain, and work toward achieving a balance instead of suppressing the symptoms.

"It's not safe to give man strength; rather, he should develop what already exists in him." 8

Several professional areas are permeated by anthroposophy (as per the Ibero-American Anthroposophical Multidisciplinary Committee - CIMA), which supports interdisciplinary work. These include Biographic Counseling, Biodynamic Agriculture, Organic Architecture, Singing Therapy, Therapeutic Education, Anthroposophical Nursing, Rhythmic Massage, ${ }^{13}$ Eurhythmy Therapy, ${ }^{14}$ Anthroposophical Medicine, ${ }^{2}$ Extra Lesson (reference to Waldorf Education), Neurofunctional Reorganization, ${ }^{15}$ Art Therapy, ${ }^{16}$ Anthroposophical Pharmacy, ${ }^{17}$ Nutrition, Anthroposophical Physiotherapy, Bothmer principles, Integral Anthroposophical Dentistry, ${ }^{8}$ Waldorf Pedagogy, ${ }^{9}$ Anthroposophical Psychology, Veterinary Medicine and Chirophonetics, among others.
It is important to mention that a book was published based on the Health Technology Assessment (HTA) report on anthroposophical medicine, commissioned by the Swiss Federal Social Security Institute and produced as part of the National Complementary Medicine Evaluation Program (PEK), addressing such issues as effectiveness, utility, costs and safety. The book described a significant improvement or cure of diseases under anthroposophical treatment, ranking it as a superior treatment method, and yielding results comparable to those of conventional therapy in 186 of the 195 clinical studies regarding anthroposophical medicine, based on the HTA. ${ }^{18}$

The anthroposophical drug therapy used in dentistry tends to eliminate expectations focusing on a "magical drug" that redeems an "evil" exclusively "from outside in." Overall, anthroposophical medicine and dentistry therapy is intended to encourage the individual to establish a probiotic action to overcome the disease, and not just remedy it, as would an antibiotic or a selective inhibitor of serotonin reuptake (SSRI) that temporarily assumes certain functions of the body, whose use may compromise the action of the very body in the long term.

Nutrition is gained from organic food, biodynamics, probiotics and anthroposophical medication therapy, and is supported by individualized treatment to stimulate the constitution so that it wins out over the disease, instead of just giving the body an outside aid.

For example, probiotics is defined by the World Health Organization as "live microorganisms which, when administered in adequate amounts, confer a health benefit on the host." Probiotics have successfully been used to control gastro-intestinal diseases, and appear to act through colonization resistance and/or immune modulation. Experimental studies and clinical trials have recently demonstrated that certain gastrointestinal bacteria may also control the growth of oral microorganisms, including cariogenic streptococci associated with disease. The oral administration of probiotics has also been explored in controlling periodontal disease (Allaker, Douglas, 2009). ${ }^{19}$

Anthroposophic pharmacy in Brazil and anthro- 
posophical medicine were validated by ANVISA, and officially recognized in Resolution 465 - DOU 16/08/2007 - pgs. 95/98. Anthroposophic pharmacy is regulated in many European countries. The medicines are made of substances from nature, and are of mineral, vegetable or animal origin. Therefore, there exists no synthetic medicine or medicine otherwise obtained from a genetically modified plant, process or culture based on pesticides, herbicides or synthetic fertilizers among the anthroposophical medicines. The cultivation of plants originating the raw material for medicinal products is organic or biodynamic, and influences their therapeutical potential. This favors and agrees with the principles of therapeutic anthroposophical dentistry.

In addition to prescribing allopathic prescriptions, the dentist must gain proper knowledge and training to be able to use anthroposophical medications, as directed, regarding not only the dyes but also the dynamic and diluted solutions. In practice, the responsibility is greater, because the professional can give the medication directly to the patient, on both physical and subtle levels of his constitution. ${ }^{8}$

\section{Discussion}

Woolf and Mannion suggest that progress in the treatment of peripheral neuropathic pain has been made in identifying the mechanisms, but not the etiological factors and the nature of the symptoms. ${ }^{20}$

Modern pathology, as viewed by philosopher Michel Foucault, is based on a complex minimalist nosological classification, which identifies a range of morbidities through the eyes of doctors and equipped pathologist.

Antonovisk ${ }^{21}$ applies the concept of salutogenesis to present a new way of formulating health issues and to direct research in this area. He considers that it is not only the stressor that deserves attention; rather, it is of equal importance to overcome the condition and the factors involved in the process, like gaining coherence and resilience.

Salutogenesis does not focus exclusively on questions aiming at identifying which is the infectious agent, or what is the remedy for healing. Instead, it gives special attention to issues like how the individual can strengthen himself or how he can become resilient.

This is not a concept that aims at preventing individual contact with the disease, and/or pain, but rather, at building human capabilities to deal with a strange situation or with a conflict, and doing this by expanding and strengthening the individual's own limits in dealing with this interaction.

Aren't the clinical procedures to gain protection from outside of the body actually preventive methods that are seen increasingly as a partial therapy, or as an arsenal directed at eradicating the disease or suppressing the pain? This arsenal includes such substances as antibiotics, antipyretics, analgesics, antihistamines, and even some so-called preventive procedures.

Some authors ${ }^{22}$ suggest that the salutogenic approach enables us to consider the cases of exceptions and deviations existing in any study or research as likely to contain sources of resources that represent the process substrates directed at health.

From a practical point of view, the integrated complementary process of anthroposophical dentistry, with its vision and remission of pain and diseases, should be incorporated into conventional clinical procedures, and be indicated on an individual basis, as needed.

\section{Conclusions}

1. Differentiated resources for dental surgeons; benefits to patients and to the government: The treatment of masticatory dysfunctions under an integration perspective. When treating the mouth, it is important to observe the phenomena occurring in other parts of the body or even at other levels. This modus operandi not only suppresses the symptoms, but helps decrease the dysfunction relapse and contributes to promoting health. Overall equilibrium and quality of life are quickly achieved at a low cost. ${ }^{23}$

2. Contribution to academism: A humanistic approach contributes to improving dentistry, especially when there is interaction between the professional and the patient, enhanced by awareness and never disregarding safety, functionality or aesthetics. Some treatment approaches may even go beyond the suppression of symptoms to em- 
brace a reduction in relapses.

3. Approach: The approach offered by Integral Anthroposophical Dentistry focuses on salutogenesis and recognizes the contribution of the important investigative dimension of pathogenic oral disease or pain, but establishes it as incomplete rather than incorrect. Disease and/or pain are conceived as resulting not only from trauma, stress or extrinsic pathogens. They are considered equally important in investigating how an

\section{References}

1. Associação Brasileira de Odontologia [homepage] Brasília (DF): Associação Brasileira de Odontologia; 2008 [cited 2012 Sep 17]. Available from: http://www.abo.org.br/revista/91/ materia7.php.

2. Cantor IR, Rosenzweig S. Anthroposophic perspectives in primary care. Prim Care. 1997 Dec;24(4):867-87.

3. Silva AM, Vargas AM, Ferreira E, Abreu MH. [The integrality of the attention in diabetics with periodontal disease]. Cien Saude Colet. 2010 Jul;15(4):2197-206. Portuguese.

4. López-Jornet P, Camacho-Alonso F, Berdugo LM. Measuring the impact of oral mucosa disease on quality of life. Eur J Dermatol. 2009 Dec;19(6):603-6.

5. Kienle GS. Klinische Forschung zur Anthroposophischen Medizin - komplette Übersicht. Der Merkurstab. 2006;59(3):272.

6. Deng G, Weber W, Sood A, Kemper KJ. research on integrative healthcare: context and priorities. Explore (NY). 2010 Jun;6(3):143-58.

7. Antonovisky, A. The salutogenic perspective: toward a new view of health and illness. Adv. 1987;4(1):47-55.

8. Galitesi Lulo, CR. O dente à imagem do homem: odontologia, Antroposofia e evolução. $2^{a}$ ed. São Paulo: Antroposófica; 2004. 182 p.

9. Galitesi Lulo, CR. Terapêuticas complementares. Rev APCD. 2007 Out;61(5):348-51.

10. Bach Jr J. Educação ecológica e a fenomenologia da natureza de Goethe e Steiner na Pedagogia Waldorf. Inter-Ação Rev Fac Educ UFG. 2008 Jun. 33(1):102-16.

11. Resende MAC, Nascimento OJM, Rios AAS, Quintanilha G, Ceballos LES, Araújo FP. Perfil da dor neuropática: a propósito do exame neurológico de 33 pacientes. Rev Bras Anestesiol. 2010 Apr;60(2):144-8.

12. Galitesi-Lulo CR. Odontologia Integral Antroposófica. Rev Odontol. 2012 Jun;17(2):20-3

13. Hamre HJ, Witt CM, Glockmann A, Ziegler R, Willich SN, Kiene H. Rhythmical massage therapy in chronic disease: a individual's intrinsic factors drive the process of overcoming adverse conditions, ultimately caused by extrinsic factors.

There is always a gain when disease or pain are overcome even in the case of a tendency toward caries formation. Otherwise, if we act solely by performing external clinical procedures, we risk relativizing the concept of prevention. ${ }^{12}$

four-year prospective cohort study. J Altern Complement Med. 2007 Aug;13(6):635-42.

14 Hamre HJ, Witt CM, Glockmann A, Ziegler R, Willich SN, Kiene H. Eurythmy therapy in chronic disease: a four-year prospective cohort study. BMC Public Health. 2007 Apr;7:61.

15. Padovan BAE. Neurofunktionelle Reorganisation - Padovan Methode. Wege zur Kommunikation - Kongressband der Diplomierten Logopädinnen für Österreich. Bundesverband der Diplomierten Logopädinnen. 1997 Sep;96(37):1-11.

16. Hamre HJ, Witt CM, Glockmann A, Ziegler R, Willich SN, Kiene H. Anthroposophic art therapy in chronic disease: a four-year prospective cohort study. Explore (NY). 2007 JulAug;3(4):365-71.

17. Gardin NE. Schleier R. Medicamentos antroposóficos: vademecum. São Paulo: João de Barro; 2009. 285 p.

18. Kienle GS, Kiene H, Albonico HU. [Anthroposophic medicine: health technology assessment report - short version]. Forsch Komplementärmed. 2006;13(Suppl 2):7-18. German.

19. Allaker RP, Douglas CWI. Novel anti-microbial therapies for dental plaque-related diseases. Int J Antimicrob Agents. 2009 Aug;33(1):8-13.

20. Woolf CJ, Mannion RJ. Neuropathic pain: etiology, symptoms, mechanisms, and management. Lancet. 1999 Jun;353(9168):1959-64.

21. Antonovsky A. The Sence of coherence: development of a research instrument. New Res Rep. 1983;32(1):1-11

22. Becker CM, Glascoff MA, Felts WM. Salutogenesis 30 years later: Where do we go from here?. Int Electronic J Health Educ. 2010 Mar;13:25-32.

23. Hamre HJ, Witt CM, Glockmann A, Ziegler R, Willich SN, Kiene H. Health costs in anthroposophic therapy users: a two-year prospective cohort study. BMC Health Serv Res. 2006 Jun;6:65. 